\title{
Effect of the Fourth Industrial Revolution on Road Transport Asset Management Practice in Nigeria
}

\author{
"Nuru Gambo 1,2 and Innocent Musonda ${ }^{2}$
}

\begin{abstract}
First submission: 23 February 2020; Accepted: 12 July 2020; Published: 30 July 2021
To cite this article: Nuru Gambo and Innocent Musonda (2021). Effect of the fourth Industrial Revolution on road transport asset management practice in Nigeria. Journal of Construction in Developing Countries, 26(1): 19-43. https://doi.org/10.21315/ jcdc2021.26.1.2.
\end{abstract}

To link to this article: https://doi.org/10.21315/jcdc2021.26.1.2

\begin{abstract}
Poor management practices of road transport assets posed a challenge to the sustainable development of the transport system in developing countries like Nigeria. Studies in the past focused mainly on the performance of road construction process. However, few studies have evaluated the effect of the fourth Industrial Revolution (4.0IR) on the road transport assets in developing countries such as Nigeria. The current study aimed at assessing the effect of the 4.0IR towards improving the management practice of road transport assets. Survey instruments were administered to project and facility managers in the Nigerian road construction sector of the economy using a proportionate random sampling technique. Partial least square structural equation modelling was used for data analysis utilising the Warp 7.0 partial least squares-structural equation modelling (PLS-SEM) software algorithm. The software calculates $p$-values with WarpPLS based on non-parametric algorithms, resampling or stable algorithms and thus does not require that the variables to be normally distributed. The study concluded that the 4.0IR drivers have a moderate effect change on the management practice of road transport assets in Nigeria at the moment. The findings imply that management of road assets in Nigeria would moderately improve due to the 4.0IR technologies resulting in transport, safety and general efficiency and effectiveness of road networks in Nigeria. The study identified the 4.0IR drivers to include robotics, mobility, virtual and augmented reality, Internet of things and cloud computing, machine learning, artificial intelligence, blockchain, three-dimensional (3D) printing drones that are built with an attached 3D printer (the drone hangs a 3D printing nozzle that has fed plastic, concrete mix or other material from a tube connected to the top of the drone's printing path that precisely plotted by software, for a promised printing accuracy of $0.1 \mathrm{~mm}$ ) and digital engineering. This study emanated from the government reports and past studies in the area of road transport asset management practice which the study investigated the major causes of poor practices and assessed the effect of the 4.0IR on the practice.
\end{abstract}

Keywords: Fourth industrial revolution, Road asset, Management practices, Nigeria

\section{INTRODUCTION}

Road transportation infrastructure assets are not only expensive to construct but also costly to manage, to satisfactorily meet public anticipation. Management of road asset infrastructure facilities is challenging particularly in developing countries because of the low level of industrialisation. An industrial revolution provides reasonable ways of managing existing assets in a way that provides maximum

\footnotetext{
'Department of Quantity Surveying, Abubakar Tafawa Balewa University Bauchi, NIGERIA 2Department of Construction Management and Quantity Surveying, University of Johannesburg, SOUTH AFRICA

*Corresponding author: gambonuru@yahoo.com
} 
benefit to the public taking into consideration limited financial resources (Estache and De Rus, 2000). This study reviewed the road transport asset management system from the perspective of the industrial revolution. Fourth Industrial Revolution (4.0IR) is positioned on the Internet of things, robotics and artificial intelligence (Li, Hou and Wu, 2017). The industrial revolution was built upon the previous industrial revolutions and uses digital revolution that has been occurring since the middle of the last century which is characterised by a fusion of technologies that is clouding the lines between the physical and digital spheres, this enables industrial organisations to rapidly automate and digitalise traditional business processes of road transport management; this enables the creation and maintenance of more intelligent products and services and ultimately transforms the global economy (Caruso, 2018). 4.0IR drivers like the Internet of things technologies are at the core of the 4.0IR transition, enabling the connected solutions that make the 4.0IR possible and reap the full benefit, road transport organisations deployed single-point Internet of things solutions and also take a comprehensive, strategic approach to reap the benefits of managing road facilities through the 4.0IR (Park, 2016).

Internet of things enables the extraction of big data from the road transport data build-up and eases road transport managers to collect a large volume of data with regards to the management of road networks (Park, 2016). It is quite important to be tactical with the data for decision making. Generally, road transport asset management is a systematic process of maintaining, upgrading and operating assets, combining engineering principles with sound business practice and economic rationale and providing tools to facilitate a more organised and flexible approach to making the decisions necessary to achieve the public's expectations (Stăncioiu, 2017). Unfortunately, poor management practice of road transport assets is one of the major factors influencing the efficient and effective road transport management in developing countries like Nigeria and hence affect the economic development of the country, leaving the country with a high rate of poor road networks which results into high traffic accidents. NBS (Nigeria Bureau of Statistics) (2018) reported that in every four hours, no fewer than two lives are lost on Nigerian roads and annually about 20,000 of the 11.654 million are involved in accidents. This is as a result of poor management practice culture for road transport asset in the country which reflects poor road networks, with a large number of potholes, over speeding, etc. The road management practice culture comprises of predictive and preventive cultures. Predictive management is a technique designed to determine the condition of a road network and estimate when maintenance should be carry-out. This approach promises cost savings over routine or timebased preventive and corrective management maintenance because tasks are performed only when warranted (Stăncioiu, 2017). Predictive management relies on data to determine road networks' likelihood of failure before it occurs. This allows asset managers to move from a road repair and replace model to a predict and fix management model using predictive analysis which relies on data, statistics, Internet of things, machine learning, artificial intelligence and modelling are used to make predictions about future outcomes (Liao et al., 2018).

Studies in the past like that of Piryonesi and El-Diraby (2020) focused on the understanding of the causes of deterioration of roads which is an important part of road asset management and uses the long-term pavement performance (LTPP) data and machine learning algorithms to predict the deterioration in the pavement condition index (PCI). The results of the study indicated that dividing data into different climatic zones can change the relative importance of attributes 
and the overall accuracy of the models. Increasing the prediction span reduces accuracy while reducing the number of prediction classes (levels of deterioration) increases accuracy. Similarly, Gunarathna and Hassan (2016) developed the road asset management sustainability assessment tool (RAMSAT) which expands the classification of transport asset beyond physical (tangible) to intangible (digital) assets. The study harmonised sustainability dimensions such as environmental, social, economic, corporate, financial and technological.

In a different study, Meyer, Amekudzi and O'Har (2010) described that the impacts of climate change on transportation infrastructure are becoming concerns to many transportation agencies. The article developed an asset management system that can be used as a decision-making framework for incorporating such concerns into a transportation agency's management approach. So also, Switzer and MCNeil (2004) stated that the interest in road transport asset management among public sector organisations has grown over the past decade, the article synthesises the research initiatives in transport asset management into policy goals and objectives and performance measures, planning and programming, programme delivery, and systems monitoring and performance results. However, these studies attempted to improve road transport asset management through sustainability or relating the practice with the effect of climate change and or providing a road map for transport asset management. The articles failed to look into the core causes of the poor practice of road transport asset management and relate the practice with the opportunities provided by the 4.0IR digitalisation process. This would enhance good road transport asset management practices in developing countries and consequently improves on the management of transport assets that would ease transport and communication, safety, efficiency and effectiveness of management process and also enhances the delivery of the assets and boost the economy of the nation.

The 4.0IR could be viewed from two angles: physical and digitalisation of assets management practice through the use of digitalisation allows managers to build a new virtual world from which we can steer the physical world (Liao et al., 2018). The 4.0IR is characterised by the merger of digitalisation and automation to make the machines intelligent, interactive and easy to use ( $\mathrm{XU}$, David and Kim, 2018). These new technologies provide a huge impact on road transport asset management practice (Syam and Sharma, 2018). Digital technologies are already making the industry's operations more efficient. Advanced digital technologies, such as the Internet of things, automation, analytics and artificial intelligence, would take core operational functions of asset management, to the next level and will augment workforce capabilities (Petrillo et al., 2018).

Therefore, this study would evaluate the effect of the 4.0IR on road transport asset management practice in Nigeria through assessing the effect of the 4.0IR on the road transport asset management practice and modelling the relationship between the 4.0IR drivers and asset management practice in Nigeria. The study set out the following research objectives:

1. To assess the effect of the 4.0IR drivers on road transport asset management practice in Nigeria.

2. To model the relationship between the 4.0IR drivers and road transport asset management practice in Nigeria. 


\section{LITERATURE REVIEW}

\section{Road Transport Asset Management Practices}

There is no single method for implementing road transportation asset management practice. Transportation agencies differ in terms of their needs and resources and the complexity of their systems (Switzer and McNeil, 2004). Typically, the first step toward implementation involves some realisation that a need for innovation change exists. However, innovation does not happen until people within the asset management practice agency, particularly managers, see the reason for the change (Piyatrapoomi, Kumar and Setunge, 2004). Taking the first step is typically difficult because it involves figuring out what needs to be done. The road transport asset management agencies presently have no common process of implementing the management practice, rather use a traditional process that outfit the unique circumstances (Schraven, Hartmann and Dewulf, 2011 ). Examples are documented in the reports of recent domestic and international scanning programmes that reviewed transportation asset management practices in agencies in Canada, England, Australia and New Zealand. For the United States, more detailed experiences of states and local highway agencies with the implementation of asset management programmes appear in a series of case studies reported Federal Highways Authorities (FHWA's Offices) of Asset Management (Beauvais et al., 2003). The following are some real-life examples from local governments, State Department of Transports (DOTs) and international organisations of their experiences in developing and implementing transportation asset management programmes.

Beauvais et al. (2003) stated that in developed countries like the United States, local governments and municipalities owned more than $75 \%$ of the nation's nearly 4 billion miles of roadways and over half of its nearly 600,000 bridges. Also, local governments typically have fewer independent systems for managing assets than state DOTs, they often have a much broader view of infrastructure assets and the goals that can be achieved through effective management of those assets (Gunarathna and Hassan, 2016). As a result, these smaller agencies may also have a greater variety of criteria and standards for judging the performance of their assets. Besides, local government agencies depend on a variety of funding sources to support the development and management of transportation assets and typically have few resources to invest in asset management programmes (Gunarathna and Hassan, 2016). Because of the large number of local government agencies in the country and the variation in the responsibilities and resources of each agency, the approaches they take to infrastructure asset management vary greatly. Gunarathna and Hassan (2016) described that asset management practice systems generally include inventory information for the asset and condition measures and values of the condition of the asset, but Lim, Porras-Alvarado and Zhang (2019) viewed performance prediction capability as the most important management practice for road transport. Martin, Davey and Clarke (2019) argued that data integrity enhances data accessibility and provide data compatibility improves management practice for road transport assets and also components in life-cycle cost analyses enable the removal of out-dated systems and unproductive assets. This considers both system and project optimisation report useful information periodically, ideally in real-time, facilitate iterative analysis processes that can be performed regularly (Burns, Hope and Roorda, 1999). 
Jraiw (2003) assessed the urban road transport management practice in Asia's developing countries with a focus on road safety and efficiency strategy. The article described that most of the world's population and economic growth is occurring in the developing countries of the Asia-Pacific region. The developing countries experienced most of the world's urban growth. Motor vehicles are growing at two to three times the population rate and the road management practice and safety are major concerns. As a consequence, countries face alarming urban road transport management challenges. The major issue is that the supply of road transport services has not matched the increased demand, because of insufficient infrastructure development. Similarly, the issue of road management practice approaches in China, Brazil and the Slovak Republic have been slightly efficient in creating expressway road networks. However, therefore there is the need by the China, Brazil and the Slovak governments to support the adoption of the 4.0IR drivers for the management of road transport to reach the optimum expressway densities for road networks Marcelino, Antunes and Fortunato (2019). In Nigeria, road transport is the most common mode of transportation and accounts for about $90 \%$ of the movement of goods and services. Most of the federal roads in Nigeria were procured decades ago by the traditional contracting system. A good number of the road-networks in many Nigerian cities are unpaved, poorly maintained, overused and impassable, thereby cutting off many rural areas from larger settlements during the rainy season, which has a corresponding negative impact on the economy due to poor management practice (Adetola and Goulding, 2016).

\section{Industrial Revolution and Road Transport Asset Management Practices}

The brink of a technological revolution which fundamentally alters the way managers practice asset management and also improve on the transformations between virtual to physical realities (Bloem et al., 2014). With this scale, scope and complexity, the transformation will be unlike anything humankind has experienced before. This development integrated and comprehensively involving all stakeholders of the global polity, from the public and private sectors to academia and civil society (Bloem et al., 2014). Studies contrast that the 4.0IR to the first industrial revolution that used water and steam to mechanise production, the second that used electric power to create mass production and the third that that used electronics and information technology to automate production (Labor, 1990). Then the 4.0IR which is the building on the third and characterised by a fusion of technologies and rapid change in technology evolution, has the potential to raise global income levels and improve the quality of life for populations around the world (Naudé, 2017). Naudé (2017) stated that to date, those who have gained the most from it have been consumers able to afford and access the digital world.

These changes are evident in transportation asset management practices. Nangoy et al. (2020) noted that the fast-moving trends are influencing urban mobility systems around the world and the shared mobility, in the form of ride-sharing services, has grown rapidly over the past few years and now competes with traditional carsharing and car-pooling providers, public transit and private vehicle ownership. Autonomous driving technology promises to improve or resolve road safety concerns, reduce the transportation facility maintenance cost, turn a percentage of all of the driving time into free time and expand access to mobility (Kalitanyi and Goldman, 2020; Gambo, Said and Ismail, 2016a). Vehicle connectedness and 
the spread of Internet of things applications into vehicles and infrastructure would generate data with various uses including real-time trip planning and guidance for private vehicle and transit users (Manesh et al., 2020). Electric vehicles continue to gain in cost competitiveness with conventional vehicles, and if the cost of renewable power generation continues to fall, intermittent distributed generation produces an increasing share of the world's electricity, possibly make energy cheaper, cleaner and more reliable. Public transit is being fitted with autonomous features that may reduce operating costs and the presence of shared vehicle fleets can make transit more convenient and accessible (Manesh et al., 2020).

Road transport asset infrastructure maintenance practice upgrades the choices that influence a modal split across private vehicles, shared transit, public transit and cycling. Sutherland (2020) indicated that in 50 metropolitan areas around the world, home to 500 million people, integrated mobility systems could produce benefits, such as improved safety and reduced pollution, worth up to USD600 billion. They also note that the transition to integrated mobility play out differently and produce different results from one city to the next because each city is unique. The pace and extent of change depending on various factors including local governance capabilities, population density, household income, public investment, the state of the road and public-transit infrastructure, and pollution and congestion levels (Sutherland, 2020). One can anticipate increasing levels of automation and connectedness as a future mobility option. Thus, while road transportation asset valuation has been based largely on the physical condition to date, it is easy to understand the importance of expanding this paradigm to include other performance factors, such as safety, mobility and resilience, to develop a superior understanding of the trade-offs among plausible alternatives and scenarios (Mazzi, 2020). Thus, the valuation of smart assets, including information and communication technologies, enabled infrastructure and connected and automated vehicles should witness an expansion of the factors used in the valuation approach.

A parallel on-going trend in the 4.0IR is growth in investment shares in intangible assets, particularly in developed economies (Mazzi, 2020). Intangible investment has become increasingly important, with new measurement methods showing how it exceeds tangible investment in some developed countries and has been growing for several decades, whereas tangible investment has steadily declined (Momotova et al., 2020). The investment share in intangibles continues to rise because of the changing balance of services and manufacturing in the economy, globalisation, increased liberalisation of markets, developments in information technology and management technologies, and the changing costs of services, which play a greater role in intangible investment (Momotova et al., 2020). With the rise of the intangible economy, one can expect to derive more worth from road transport asset infrastructure valuation approaches that aim to include intangible value defensibly. Thus, transportation asset valuation should not only expand to include factors other than condition, but it should also aim to capture intangibles such as resilience, liveability and sustainability (Ng, 2020).

\section{Technological Drivers of the 4.0IR}

The development of digital innovation technology is one of the fundamental technological drivers of the 4.0IR; the 4.0IR is driven by enduring breakthroughs in this area within the respective area as well as a great fusion with each 
technological driver. Digital innovation is a process of making rapid change by using technology to enhance services, traditional models, products and processes through understanding end-user needs (Simmons, Palmer and Truong, 2013). The technological drivers for the 4.0IR mainly originate from the software field. Digital innovation technology is the fundamental driving force for the 4.0IR and nearly all the innovations and advances coming with the 4.0IR flow are made possible and enhanced through digital power (Peters, 2017). This technology cluster is making the whole world a digitally connected one. The digital innovations technology includes; the Internet of things, artificial intelligence and machine learning, big data and cloud computing, blockchain and other digital platforms (Peters, 2017).

The evolution of the Internet of things has gone beyond Internet-connected appliances but it is seen as the integration of technologies like machine learning, embedded systems and wireless (Li, Hou and Wu, 2017). The Internet of things is pivotal to the inception and evolution of the 4.0IR. The sensors in networked physical connected devices collect data in real-time (Peters, 2017). This is very valuable to road transport management practice businesses and can help optimise the management practice through automation and management of vast road networks with ease and accuracy. Using advanced analytics, the use of big data in the management practice of road networks is transformed into meaningful information to meet business objectives (Li, Hou and WU, 2017). Transport managers could have better means to organise, analyse and seek the real value of their big data for better business achievement. Cloud computing offers a flexible and affordable way to support road transport management business operations. This is achieved from remote working and backing up information to storing large data sets. Smart machines like expert systems, digital assistants and autonomous devices are changing transportation industry processes (Li, Hou and WU, 2017).

Advancements in robotics and artificial intelligence are changing transportation industry; the emerging technologies have an impact on employees and there is need to focus on how workers and machines can work together for better results (Li, Hou and Wu, 2017). Blockchain is a powerful methodology for tracking and transactions that will impact the industry commercial activities in a wide variety of ways. Three-dimensional (3D) printing drones are already impacting on the other sectors of the global economy such as buildings, agriculture, making dangerous jobs safer, providing a lifeline for remote populations, meeting refugee emergencies, and revolutionising how people and goods are transported (Morrar, Arman and Mousa, 2017).

\section{Physical Drivers of the 4.0IR}

Physical innovation in the road transport management practice has visible achievements, rapid applications and broad prospects are physical known technology drivers of the 4.0IR since it has the most direct impacts on daily lives. Physical innovation refers to a new method or change made to an existing physical process for the management practice of road transport system (Jazdi, 2014). The physical innovation drivers for the management practice of road transport includes innovation process, creation of support team, psychological climate for new ideas and leverage diversity (Emmanouilidis and Komonen, 2013), but Gaetani et al. (2017) viewed that the building of a culture of innovation coupled with organisational culture enhance physical innovation process. Li, Hou and Wu 
(2017) argued that the physical environment and favourable economic climate coupled with good leadership strategy enhances physical innovation process.

\section{RESEARCH METHODOLOGY}

This study explores literature to gain insights and ideas about the effects of the 4.0IR on the road transport asset management practice in Nigeria as well as understand the variables and issues surrounding them. Subsequently, literature findings were used to adapt a structured questionnaire that was used to elicit information on the three study constructs: 4.0IR drivers, physical drivers and asset management practice. Thus, the study design is quantitative (McNabb, 2015). The study area is the road transport asset in the northern geopolitical zone of Nigeria. The zone comprised of 19 states and the administrative headquarters of Nigeria, Abuja. The zones occupy almost $70 \%$ of the total landmass of the country $(744,249.08 \mathrm{sq} . \mathrm{km})$ and home to slightly more than half $(74.2 \mathrm{~m})$ of Nigeria's population (170 million) (Gambo, Said and Ismail, 2016b; Gambo, Said and Inuwa, 2017).

The NBD (Nigerian Business Directory) (2019) was used to arrive at a population of 1,777 comprising of the public and private project and facility managers that are presently involved in the execution of road transport asset management in the northern geopolitical zone of Nigeria. Afterwards, a sample size of 317 respondents was determined using Krejcie and Morgan (1970) rule of thumb. Subsequently, questionnaires were administered to the respondents through a proportionate random sampling technique. This technique was adopted because of the uneven distribution of the study population (unequal proportionate number of respondents in the 19 states of the study area). This had not influenced the outcome of the study because the proportionate random sampling method was used in the data collection, hence biases in the study were also avoided (Sekaran and Bougie, 2011). A total of 276 valid questionnaires were returned while 26 were rejected. Thus, not included in the analysis because of discrepancies in the responses and/or majority of the items in the questionnaire were left unattended or unanswered. The survey records approximately $67 \%$ of valid response rates.

The primary research tool for this study was a self-administered questionnaire. The questionnaires were administered to the study respondents. Questions asked were closed and ended (Guthrie, 2010). Questions on the study objectives were captured by three constructs (i.e., latent variables) (as shown in Table 1): road transport asset management practice (ASSMGT) as the dependent variable while physical innovation factors (PHYINN) and digital innovation (DIGINN) are independent variables, respectively. The measurement items for construct ASSMGT were adapted from Burns, Hope and Roorda (1999), Switzer and McNeil (2004), Schraven, Hartmann and Dewulf (2011), Gunarathna and Hassan (2016), Lim, Porras-Alvarado and Zhang (2019) and Martin, Davey and Clarke (2019) while the construct PHYINN was adapted from the studies of Jazdi (2014), Emmanouilidis and Komonen (2013), Gaetani et al. (2017) and Li, Hou and Wu (2017). The construct DIGINN was adapted from the studies of Simmons, Palmer and Truong (2013), Peters (2017), Li, Hou and Wu (2017) and that of Morrar, Arman and Mousa (2017). All the variables were measured on a 5-point Likert scale. Partial least squaresstructural equation modelling (PLS-SEM), using WarpPLS 7.0 (Kock, 2016), was 
used to analyse the data obtained and to examine the effect of the relationship among the constructs through the development of conceptual framework into a model. Warp PLS-SEM facilitates theory building in studies that seek to explore causal relationships between latent variables over covariance-based squaresstructural equation modelling (CB-SEM) that is generally used to confirm theory (Hair, Ringle and Sarstedt, 2011). Moreover, PLS-SEM was employed for the analysis because of its high predictive ability and for examining the validity of reflectively measured constructs (Hair et al., 2014; Hazen et al., 2014). The conceptual framework is as shown in Figure 1.

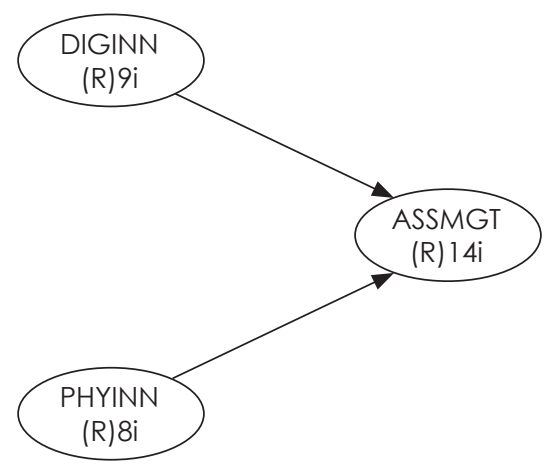

Figure 1. Conceptual Framework

Table 1. Development of the Constructs for the Study

\begin{tabular}{|c|c|c|}
\hline$S / N$ & Constructs & Source \\
\hline A & Asset Management Practice (ASSMGT) & \\
\hline A. 1 & Asset inventory information & $\begin{array}{l}\text { Burns, Hope and Roorda (1999) } \\
\text { Switzer and McNeil (2004) }\end{array}$ \\
\hline A. 2 & Asset condition measures & $\begin{array}{l}\text { Schraven, Hartmann and Dewulf } \\
\text { (2011) }\end{array}$ \\
\hline A.3 & Values of condition of asset & Gunarathna and Hassan (2016) \\
\hline A.4 & Performance prediction capability & $\begin{array}{l}\text { Lim, Porras-Alvarado and Zhang } \\
\text { (2019) }\end{array}$ \\
\hline A. 5 & Asset data integrity & Martin, Davey and Clarke (2019) \\
\hline A.6 & Data compatibility & Martin, Davey and Clarke (2019) \\
\hline A.7 & Life cycle cost analyses & $\begin{array}{l}\text { Schraven, Hartmann and Dewulf } \\
\text { (2011) }\end{array}$ \\
\hline A.8 & Enable and removal of outdated system & Beauvais et al. (2003) \\
\hline A.9 & Removal of unproductive practice & Gunarathna and Hassan (2016) \\
\hline A. 10 & System and project optimisation & $\begin{array}{l}\text { Lim, Porras-Alvarado and Zhang } \\
\text { (2019) }\end{array}$ \\
\hline
\end{tabular}


Table 1. Continued

\begin{tabular}{|c|c|c|}
\hline$S / N$ & Constructs & Source \\
\hline A. 11 & Periodic information review & $\begin{array}{l}\text { Martin, Davey and Clarke (2019) } \\
\text { and Lim, Porras-Alvarado and } \\
\text { Zhang (2019) }\end{array}$ \\
\hline A. 12 & Iterative analysis process & Burns, Hope and Roorda (1999) \\
\hline A.13 & $\begin{array}{l}\text { Decision making under certainty, risks } \\
\text { and uncertainty }\end{array}$ & $\begin{array}{l}\text { Jraiw (2003) and Lim, Porras- } \\
\text { Alvarado and Zhang (2019) }\end{array}$ \\
\hline A. 14 & Financial and investment returns & $\begin{array}{l}\text { Adetola and Goulding (2016) } \\
\text { and Jraiw (2003) }\end{array}$ \\
\hline B & Physical Innovation Drivers (PHYINN) & \\
\hline B. 1 & Physical innovation development process & Jazdi (2014) \\
\hline B.2 & Creating innovation support team & $\begin{array}{l}\text { Emmanouilidis and Komonen } \\
\text { (2013) }\end{array}$ \\
\hline B. 3 & Psychological climate (new idea) & Gaetani et al. (2017) \\
\hline B.4 & Leverage diversity & Li, Hou and Wu (2017) \\
\hline B. 5 & Building culture of innovation & $\begin{array}{l}\text { Emmanouilidis and Komonen } \\
\text { (2013) and Li, Hou and Wu (2017) }\end{array}$ \\
\hline B.6 & Organisational culture & Gaetani et al. (2017) \\
\hline B.7 & Physical environment & $\begin{array}{l}\text { Jazdi (2014) and Li, Hou and Wu } \\
\text { (2017) }\end{array}$ \\
\hline B.8 & $\begin{array}{l}\text { Economic environment and leadership } \\
\text { strategy }\end{array}$ & Li, Hou and Wu (2017) \\
\hline C & Digital Innovation Drivers (DIGINN) & \\
\hline C.1 & Internet of things & $\begin{array}{l}\text { Simmons, Palmer and Truong } \\
(2013)\end{array}$ \\
\hline C.2 & Robotics & Peters (2017) \\
\hline C.3 & Virtual and augmented realities & Li, Hou and Wu (2017) \\
\hline C.4 & Cloud computing & Morrar, Arman and Mousa (2017) \\
\hline C.5 & Artificial intelligence & $\begin{array}{l}\text { Simmons, Palmer and Truong } \\
\text { (2013) }\end{array}$ \\
\hline C.6 & 3D printing drones & Peters (2017) \\
\hline C.7 & Mobility & Li, Hou and Wu (2017) \\
\hline C.8 & Blockchain & Morrar, Arman and Mousa (2017) \\
\hline C.9 & Machine learning & $\begin{array}{l}\text { Simmons, Palmer and Truong } \\
\text { (2013) }\end{array}$ \\
\hline
\end{tabular}

The research constructs cover road transport asset management practice, physical innovation drivers and digital innovation drivers of the 4.0IR all measured using the 5-point Likert scale. The Likert scale is concerned with unidimensionality and is also the most popular scaling procedure that is commonly 
used in the social sciences (Guidici, 2003; Oppenheim, 2000). The construct asset management practice was the dependent construct and was operationalised from very low management practice to very high management practice. The independent constructs, i.e. the physical and digital innovations, were operationalised using very low impact to very high impact. The operationalisation process was adapted from the studies of Team Leadership (2010) and that of Sumner and Slattery (2010). The data for this study was collected through a self-administered questionnaire that was returned and analysed using partial least square structural equation modelling PLS-SEM algorithms.

\section{RESULTS}

\section{Respondents Demographic Information}

Table 2 depicts the respondents' demographic profiles. $50.72 \%$ of the respondents are project/facility managers working in the public sector of the economy while $49.28 \%$ of the respondents are working in the private sector. This result shows that both the public and private sector of the economy is involved in the management of road transport asset facilities in Nigeria. However, the public sector is more involved than in the private sector. Thus, there is an expectation of transparency and accountability in their dealings. All the respondents hold at least a bachelors' degree in construction-related disciplines. Only about $13.77 \%$ of the respondents are Doctors of Philosophy (PhD) holders and about $39.86 \%$ have Masters of Science (Msc) degrees while almost $46.37 \%$ of the respondents hold Bachelors of Science (Bsc) degrees as their highest educational qualification. This shows that all the respondents are educationally qualified to respond to the research of this nature and as such, enhanced the validity of the research data. Also, Table 2 reveals that the study respondents have an average of 12.5 years' working experience in the road asset management practice; this implied that the professionals are very experienced in the area of this research. Overall, the mean of years of experience, $\Sigma f x / \Sigma f=3,450 / 276=12.5$ years' mean experience.

Table 2. Respondents Demographic Profile

\begin{tabular}{lccc}
\hline Project Managers & No. & $\%$ & Cumulative \% \\
\hline Public sector & 140 & 50.72 & 50.72 \\
Private sector & 136 & 49.28 & 100.00 \\
\hline Total & 276 & 100.00 & \\
\hline Educational Qualifications & & & \\
PhD & 38 & 13.77 & 13.77 \\
MSc & 110 & 39.86 & 53.63 \\
BSC & 128 & 46.37 & 100.00 \\
\hline Total & 276 & 100.00 & \\
\hline
\end{tabular}


Table 2. Continued

\begin{tabular}{lcccr}
\hline \multicolumn{5}{c}{ Years of Experience } \\
\hline Years & Mid Value $(x)$ & Frequency $(f)$ & \% of Frequency & \multicolumn{1}{c}{$f x$} \\
\hline 5 to 10 & 7.5 & 58 & 21.01 & 435 \\
10 to 15 & 12.5 & 102 & 36.96 & 1,275 \\
15 and above & 15.0 & 116 & 42.03 & 1,740 \\
\hline Total & & 276 & 100.00 & 3,450 \\
\hline
\end{tabular}

\section{Model Fit Indices}

Past studies provided basic sets of guidelines and recommendations for information that should be included in any manuscript that has confirmatory factor analysis as the primary statistical analysis techniques, such indices includes chi-square $\left(x^{2}\right)$, alike information criteria $(A I C)$, comparative fit, Parsimonious fit, goodness-of-fit index, standardised root mean square residual (SRMR), BentlerBonett or normed fit index (NFI) and root mean square error (RMSE) (Schreiber et al., 2006; Davcik, 2014; Hair et al., 2014; Hazen, Overstreet and Boone, 2015; Xiong, Skitmore and Xia, 2015). However, Kock (2012) stated that there is a philosophical straight forward distinction between CB-SEM and PLS-SEM, if the research objective is theory testing and confirmation, then the appropriate method is CB-SEM. In contrast, if the research objective is prediction and theory development, then the appropriate method is PLS-SEM. Conceptually and practically, PLS-SEM is similar to using multiple regression analysis. On the interpretation of the model fit, if the goal is to only test hypotheses, where each arrow represents a hypothesis and then the model fit indices are of little importance. However, if the goal is to find out whether one model has a better fit with the original data than another, then the model fit indices are a useful set of measures related to model quality (Kock, 2012).

However, PLS-SEM software algorithms reported the following indices: The fit indices are used to compare the indicator correlation matrices such as the standardised root mean squared residual (SRMR), standardised mean absolute residual (SMAR), standardised chi-squared (SChS), standardised threshold difference count ratio (STDCR) and standardised threshold difference sum ratio (STDSR). As with the classic model fit and quality indices, the interpretation of these indices depends on the goal of the SEM analysis. Since these indices refer to the fit between the model-implied and empirical indicator correlation matrices, they become more meaningful when the goal is to find out whether one model has a better fit with the original data than another, particularly when used in conjunction with the classic indices (Kock, 2012). When assessing the model fit with the data, several criteria are recommended as follows. Average path coefficient $(A P C)=0.454, p<0.001$, average $R$-squared $(A R S)=0.619, p<0.001$, then average adjusted $R$-squared (AARS) was 0.616, $p<0.001$, the average block variance inflation factor $(A V I F)=1.333$, acceptable if $\leq 5$, ideally $\leq 3.3$, the average full collinearity VIF (AFVIF) $=2.071$, acceptable if $\leq 5$, ideally $\leq 3.3$, VIF are used when indicators are formative. Tenenhaus goodness of fit (GoF) $=0.555$, small $\geq 0.1$, medium $\geq 0.25$, large $\geq 0.36$ then GoF is regarded as large, GoF is the geometric 
mean of the average communality (outer measurement model) and the average $R^{2}$ of endogenous latent variables, represents an index for validating the PLS model globally, as looking for a compromise between the performance of the measurement and the structural model, respectively. The Sympson's paradox ratio $(S P R)=1.000$, acceptable if $\geq 0.7$, ideally $=1$. Therefore, it is acceptable in this study. The $R$-squared contribution ratio $(R S C R)=1.000$, acceptable if $\geq 0.9$, ideally $=1$, it is regarded as ideal in this study. The statistical suppression ratio $(S S R)=1.000$, acceptable if $\geq 0.7$, so it is acceptable in this study. Nonlinear bivariate causality direction ratio $(N L B C D R)=1.000$, acceptable if $\geq 0.7$, which is regarded as acceptable in this study. The standardised root means square residual (SRMR) value for this model was 0.07 which indicated a good fit (Hu and Bentler, 1999). Bentler-Bonett or NFI was 0.98 which was considered good (Bentler and Bonett, 1980). The RMSE for this model was 0.05 and regarded as good according to (Maccallum, Browne and Sugawara, 1996). Therefore, this model has a good fit index.

\section{MODEL ASSESSMENT USING WARP 7.0 PLS-SEM}

Table 3 is resulted from the assessment of the model by Warp 7.0 PLS-SEM analysis which typically follows two steps, namely: the assessment of the structural model (Chin, 2010; Hair, Ringle and Sarstedt, 2011) and reflective measurement model. The assessment of the measurement model examines the validity and reliability of the measurement instrument and relationship among the constructs. The model for this study has three reflective constructs namely: road transport asset management practice, physical innovation and digital innovations of an asset. The reflective measurement model evaluates the reliability and validity of the model. The two criteria are composite reliability (CR) and the average variance extracted (AVE) (Chin, 2010; Hair, Ringle and Sarstedt, 2011). This study used the internal consistency test to assess the reliability of the research instrument. According to Field (2016), Cronbach's alpha $(\alpha)$ tests the questionnaire's construct consistency and level of random error. The use of Cronbach's a allows the negative construct to be detected and positive to be accepted ranging from a scale of 0 to 1.0 (Pallant, 2011). The minimum acceptable value for Cronbach's alpha is from 0.6 (Field, 2016; Pallant, 2011). Once an item is to be used together as a scale in this study, the item must be within the benchmark value of reliability indicators. Ho (2006) stated that the reliability of a measuring instrument is defined as its ability to consistently measure the phenomenon it is designed to measure. Reliability, therefore, refers to test consistency. The importance of reliability lies in the fact that it is a prerequisite for the validity of a test. The internal consistency tests comprise of split-half technique, item analysis and Cronbach's alpha method. One of the shortcomings of Cronbach's alpha is that it usually under-estimates the reliability of a construct with small sample size $(<100)$, but construct with large sample size (> 100) Cronbach alpha is used to estimates the internal consistency of the construct (Chin and Newsted, 1999). However, Ho (2006) recommended Cronbach's alpha test as the most reliable among others. Cronbach's alpha test provides a unique estimate of the internal consistency or reliability of a scale, rather than there being a range of possible reliabilities. 
Table 3. Results of the Measurement Model Evaluation

\begin{tabular}{|c|c|c|c|c|c|}
\hline Construct & Items & Factor Loading & CR & Cronbach's Alpha & AVE \\
\hline ASSMGT & $\begin{array}{l}\text { A. } 1 \\
\text { A. } 2 \\
\text { A. } 3 \\
\text { A. } 4 \\
\text { A. } 5 \\
\text { A. } 6 \\
\text { A. } \\
\text { A. } 8 \\
\text { A. } 9 \\
\text { A. } 10 \\
\text { A. } 11 \\
\text { A. } 12 \\
\text { A. } 13 \\
\text { A. } 14\end{array}$ & $\begin{array}{l}0.932 \\
0.948 \\
0.910 \\
0.932 \\
0.944 \\
0.907 \\
0.981 \\
0.903 \\
0.955 \\
0.930 \\
0.922 \\
0.935 \\
0.975 \\
0.830\end{array}$ & 0.723 & 0.724 & 0.725 \\
\hline PHYINN & $\begin{array}{l}\text { B. } 1 \\
\text { B. } 2 \\
\text { B. } 3 \\
\text { B. } 4 \\
\text { B. } 5 \\
\text { B. } 6 \\
\text { B. } 7 \\
\text { B. } 8\end{array}$ & $\begin{array}{l}0.998 \\
0.740 \\
0.724 \\
0.733 \\
0.718 \\
0.731 \\
0.731 \\
0.734\end{array}$ & 0.945 & 0.933 & 0.883 \\
\hline DIGINN & $\begin{array}{l}\text { C. } 1 \\
\text { C. } 2 \\
\text { C. } 3 \\
\text { C. } 4 \\
\text { C. } 5 \\
\text { C. } 6 \\
\text { C. } \\
\text { C. } 8 \\
\text { C. } 9\end{array}$ & $\begin{array}{l}0.711 \\
0.722 \\
0.753 \\
0.754 \\
0.754 \\
0.738 \\
0.736 \\
0.711 \\
0.788\end{array}$ & 0.818 & 0.754 & 0.843 \\
\hline
\end{tabular}

Therefore, the indicator and construct reliability were assessed to evaluate the reliability of the reflective measurement model for structural equation modelling. The indicator reliability was evaluated by cross-checking the loading of each indicator variable on its associated latent construct and the loading should be higher or more than 0.70 before accepting the reliability of the indicator variable (Hulland, 1999; Hair, Ringle and Sarstedt, 2011). For the assessment of construct reliability, two coefficients are considered, i.e. CR and the Cronbach's alpha (Bagozzi and Yi, 1988; Cohen, 1988; Chin, 2010). Hair et al. (2014) recommended CR for PLS-SEM. Table 3 shows the results of the measurement model of this study which indicated high internal consistency and reliability. The indicators loadings were all well $>0.70$ and both the CR and Cronbach's alpha are ranged from 0.929 to 0.971 and 0.917 to 0.966 , respectively. This shows that all the indicators and constructs' reliability are acceptable. The convergent and discriminant validity are also considered in the validation of the reflective measurement model (Hair, Ringle and Sarstedt, 2011). The AVE values of the constructs must be greater than 0.5 for an accepted convergent validity (Bagozzi and Yi, 1988; Hair, Ringle and Sarstedt, 2011). The AVE is only applicable for 
models with reflective indicators. AVE measures the total variance of a construct through its indicators (Chin, 2010). The AVE values for this study are higher than 0.70 as well as the loadings of the indicators. Therefore, the convergent validity of the measurement model is highly acceptable (Davcik, 2014).

\section{DISCRIMINANT VALIDITY TEST}

Table 4 indicates the discriminant validity of the measurement model. The discriminant validity is the extent to which construct is distinguished from other constructs in the model (Chin, 2010; Hair, Ringle and Sarstedt, 2011). This is achieved through checking of the AVE of each construct and must be higher than the highest squared correlation of the construct of any other construct in the model or the loading of an indicator with its associated construct must be higher than that with other constructs (Chin, 2010; Hair, Ringle and Sarstedt, 2011; Fornell and Lacker, 1981). The results indicated that the square root of AVE for each construct with its correlation to another construct is acceptable discriminant validity of the measurement model. Based on the results of the measurement model the questionnaires were acknowledged to be reliable and valid for the assessment of the three study constructs.

Table 4. Results for Discriminant Validity

\begin{tabular}{lccc}
\hline & ASSMGT & PHYINN & DIGINN \\
\hline ASSMGT & 0.873 & & \\
PHYINN & 0.723 & 0.871 & \\
DIGINN & 0.641 & 0.711 & 0.932 \\
\hline
\end{tabular}

Note: Discriminant validity showing AVE.

\section{MEASURES AND PATH COEFFICIENTS OF THE MODEL}

Figure 2 indicates the $R^{2}$ measure of endogenous latent variables (constructs) and the path coefficients of the model. The model is evaluated as a part of a preliminary assessment of structural relationship, i.e. inner model and hypothetical framework (Chin, 2010, Hair et al., 2014). Therefore, Chin (1998) suggested 0.67, 0.33 and 0.19 as substantial, moderate and weak measures for $R^{2}$, respectively. The $R^{2}$ for this study was 0.62 which indicated a moderate relationship between criterion and predictor variable. The influence of PHYINN on ASSMGT was also having $\beta_{\text {value }}-0.48$ with a $p<0.00$ significant at $p \leq 0.05$ level. This means that a moderate negative influence exists between the construct (Cohen, 1988). Thus, implies an increase in PHYINN led to a non-linear decrease in ASSMGT. Similarly, the path coefficient between DIGINN and ASSMGT was having a $\beta_{\text {value }}$ of 0.43 , respectively. Thus, indicating moderate influence (Cohen, 1988) with a $p<0.00$ significant at $p \leq 0.05$ level of significance. This implies that an increase in DIGINN would lead to an increase in the level of road transport asset management practice in Nigeria. 


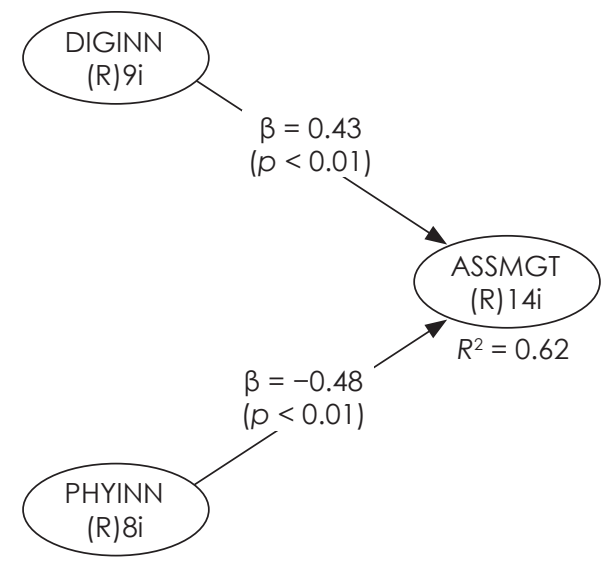

Figure 2. Assessment Results for the Structural Model

Table 5 indicates the effect size $\left(f^{2}\right)$ which is a measure that verifies whether the effects indicated by the path coefficient are low, moderate or high for the values of $f^{2} 0.02,0.15$ and 0.35 , respectively (Cohen, 1988). Effect size $\left(f^{2}\right)$ indicates the effect of a certain construct on the dependent latent variable is substantial (Chin, 2010). The $f^{2}$ between PHYINN and ASSMGT is 0.331 which indicated a moderate effect. The $f^{2}$ between DIGINN and ASSMGT was 0.288 also indicates moderate effect sizes, respectively. The predictive competency of each endogenous construct in the model was determined by Stone-Geisser's (crossvalidated redundancy) ( $\left.Q^{2}\right)$ (Hair, Ringle and Sarstedt, 2011). The predictive skill of this model was 0.621 and Warp PLS-SEM automatically generates $Q^{2}$ (Kock, 2012). Hazen et al. (2014) reported that $Q^{2}$ values indicate the predictive relevance as either weak (0.02), moderate (0.15), or strong (0.35). Therefore, this model exhibit strong predictive relevance because of the $Q^{2}>0$, i.e. about 0.621 (Chin, 2010). Thus, indicates the path model's predictive relevance on the endogenous construct is strong (Hair, Ringle and Sarstedt, 2011; Hazen et al., 2014). This implies that the two predictors (digital and physical innovators) predict $62 \%$ of the variance of the dependent variable (road transport asset management practice).

Table 5. Hypotheses-Testing Results

\begin{tabular}{lccccc}
\hline Hypotheses & $\begin{array}{c}\text { Path } \\
\text { Coefficient }\end{array}$ & $\boldsymbol{p}$-Value & $\begin{array}{c}\text { Effect } \\
\text { Size }\left(\boldsymbol{f}^{2}\right)\end{array}$ & $\begin{array}{c}\text { Stone-Geisser's } \\
\left(\boldsymbol{Q}^{2}\right)\end{array}$ & Supported \\
\hline PHYINN $\rightarrow$ ASSMGT & -0.477 & $<0.001$ & 0.288 & 0.621 & Yes \\
DIGINN $\rightarrow$ ASSMGT & 0.431 & $<0.001$ & 0.331 & & Yes \\
\hline
\end{tabular}

Note: Level of significance $(p) \leq 0.05 ; Q^{2}$-cross-validated redundancy. 


\section{Graphical Relationships amongst the Study Construct}

Figure 3 presents a graph of DIGINN and ASSMGT. The graph indicated that a non-linear relationship exists between DIGINN and the ASSMGT construct. The relationships impliedly indicated a positive relationship which means that an increase in DIGINN would lead to an increase in ASSMGT. The coordinates' points $\left(x_{0}, y_{0}\right.$ and $\left.x_{1}, y_{1}\right)$ and the regression line of the graph were $(-3.06,-2.43$ and 1.50 , $0.63)$.

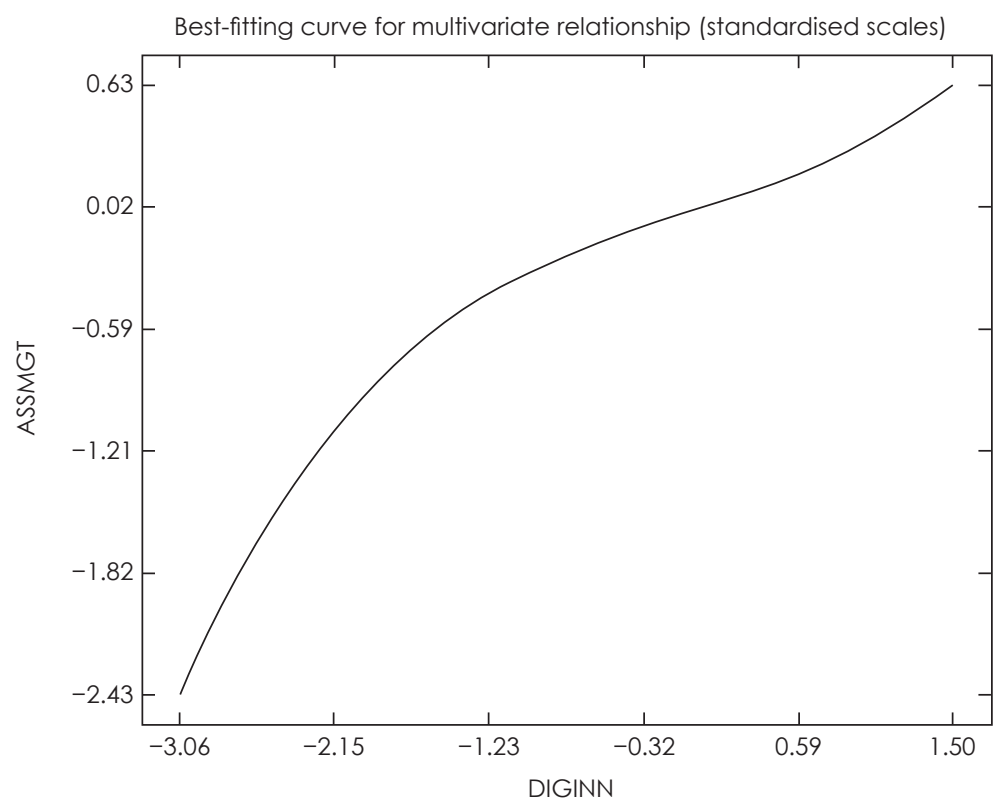

Figure 3. Relationship of DIGINN and ASSMGT

Figure 4 presents a graph of PHYINN and ASSMGT. The graph indicated that a non-linear relationship exists between PHYINN and the ASSMGT construct. The relationships impliedly indicated a negative relationship which means that an increase in PHYINN would lead to a decrease in ASSMGT. The coordinates' points $\left(x_{0}, y_{0}\right.$ and $\left.x_{1}, y_{1}\right)$ and the regression line of the graph were $(-0.80,0.28$ and 3.46 , $-1.89)$. 


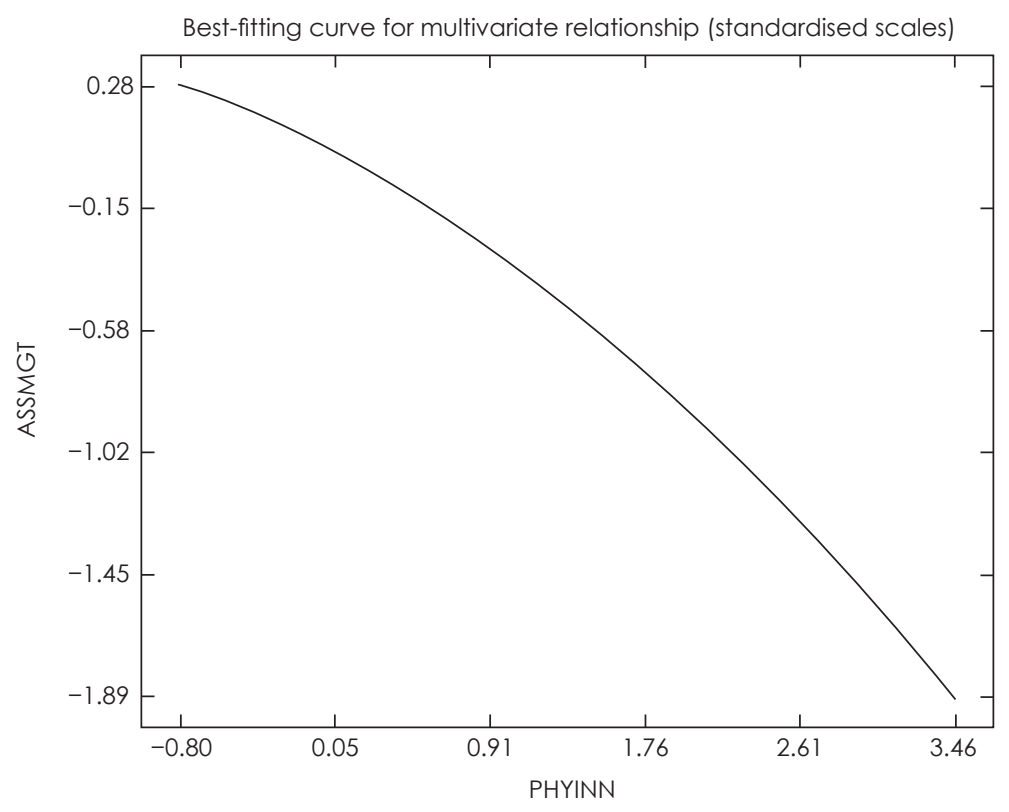

Figure 4. Relationship of PHYINN and ASSMGT

\section{DISCUSSIONS}

This study assessed the effect of 4.0IRs on the asset management practice in Nigeria. Two constructs were considered as a predictor or independent variables that predict the outcomes of the dependent variable, i.e. the road transport asset management practice. The constructs namely, physical innovation of road transport asset indicators were identified from studies of Jazdi (2014), Emmanouilidis and Komonen (2013), Gaetani et al. (2017) and Li, Hou and Wu (2017). The indicators of digital innovation were identified and adapted from the studies of Simmons, Palmer and Truong (2013), Peters (2017), Li, Hou and Wu (2017) and Morrar, Arman and Mousa (2017). The constructs were chosen based on the classification by Caruso (2018) that categorised drivers of the 4.0IR the 4.0IR as being physical and digital drivers.

The 4.0IR builds on the previous revolutions and uses digital revolution that commenced in the middle of the 20th century. It is characterised by a fusion of technologies that is clouding the lines between the physical and digital spheres, enables industrial organisations to rapidly automate and digitalise traditional business processes of road transport management practice for example. The technologies enable the creation and maintenance of more intelligent products and services and ultimately transforms the global economy.

Using the road transport asset management practice as the dependent construct and using variables identified from Burns, Hope and Roorda (1999), Switzer and McNeil (2004), Schraven, Hartmann and Dewulf (2011), Gunarathna and Hassan (2016), Lim, Porras-Alvarado and Zhang (2019) and Martin, Davey 
and Clarke (2019), the effect of the 4.0IR was assessed. Specifically, the empirical study focused on the effects of 4.0IR on the asset management practices in Nigeria. The measurement model exhibited a consistent, reliable and valid questionnaire. Equally, the results of the analysis indicated a moderate effect between the independent constructs (PHYINN and DIGINN) and the dependent construct (ASSMGT). The path coefficients for the model were all significant. This supported the findings of (Switzer and McNeil, 2004). However, the findings seemed to contradict the findings of (Schraven, Hartmann and Dewulf, 2011) on the physical factors influencing asset management practice possibly for the reasons that the study considered building infrastructure projects only. Moreover, as suggested by Li, Hou and Wu (2017), government support and capacity is critical to realising greater benefits. This was the view of Benassi et al. (2020) that benefits from technology take time to realise.

Nonetheless, all the hypotheses developed for this study were supported. The graphs indicated non-linear relationships exist between the independent and the dependent constructs. The relationship between PHYINN and ASSMGT shows a negative relationship which implies that an increase in PHYINN leads to a decrease in ASSMGT. While for the relationship between DIGINN indicated a positive non-linear relation that implies that an increase in DIGINN leads to an increase in ASSMGT, respectively.

\section{CONCLUSION}

The study aimed at assessing the effect of 4.0IRs on the road transport asset management practice in Nigeria with the view of improving road transport asset management practice in the country. The assessment of the effect is valuable for future improvement in the successful management of transport asset and maintenance delivery, as well as the enhancement of the infrastructure lifetime. The results identified areas of digitalisation for improvement of road transport asset management practice such as robotics, mobility, virtual and augmented reality, Internet of things and cloud computing, machine learning, artificial intelligence, blockchain and 3D printing drones, and the digital engineering. These are the drivers of 4.0IRs and are vital and as well as effective for the management of transport asset management practice particularly in developing countries like Nigeria. The results indicated a moderate effect change as regards to the digitalisation of road asset transport management practice. This means that increase use of digitalisation would enhance about $43 \%$ better management practice of assets in Nigeria which implies that moderate improvement in road asset management could be achieved with the optimum application of digitalisation innovation drivers. The study is limited to the application of the 4.0IR drivers (digital and physical drivers) to road transport asset management practice in Nigeria and consequently, the study recommends the adoption of 4.0IR drivers for road transport asset management for the transformation of the Nigerian road networks. It must also be fully realised that benefits may not be immediate but as the study has established, they are evident. Consequently, the study, recommends further and continuous studies on the potentials of the 4.0IR drivers for management of road transport asset practice in order to fully realise the potential that the technologies offer. 


\section{REFERENCES}

Adetola, A. and Goulding, J. (2016). A collaborative framework for road infrastructure management. Infrastructure Asset Management, 3(2): 71-80. https://doi.org/10.1680/jinam.14.00025.

Bagozzi, R.P. and Yi, Y. (1988). On the evaluation of structural equation models Journal of the Academy of Marketing Science, 16(1): 74-94. https://doi.org/ 10.1007/BF02723327.

Beauvais, J.C., Lam, J.C., Lee, M.J., Reis, V.C., Haimes, Y.Y. and Lambert, J.H. (2003). Asset management for Virginia highways and roads. In IEEE Systems and Information Engineering Design Symposium, 2003. Charlottesville, VA: IEEE (Institute of Electrical and Electronics Engineers), 269-274. https://doi .org/10.1109/SIEDS.2003.158034.

Benassi, M., Grinza, E., Rentocchini, F. and Rondi, L. (2020). Going revolutionary: The impact of 4IR technology development on firm performance. SEEDS working paper 07/2020, 1-39. Available at: http://www.sustainability-seeds.org/ papers/RePec/srt/wpaper/0720.pdf.

Bentler, P.M. and Bonett, D.G. (1980). Significance tests and goodness of fit in the analysis of covariance structures. Psychological Bulletin, 88(3): 588-606. https://doi.org/10.1037/0033-2909.88.3.588.

Bloem, J., Van D., Menno, D.S., Excoffier, D., Maas, R. and Van, O.E. (2014). The fourth industrial revolution: Things to tighten the link between IT and OT. In VINT Research Report 3. Paris: Sogeti Global Headquarters, 8. Available at: https://www.sogeti.com/globalassets/global/special/sogeti-things3en.pdf.

Burns, P., Hope, D. and Roorda, J. (1999). Managing infrastructure for the next generation. Automation in Construction, 8(6): 689-703. https://doi.org/10 .1016/S0926-5805(98)00115-0.

Caruso, L. (2018). Digital innovation and the fourth industrial revolution: Epochal social changes? Ai and Society, 33(3): 379-392. https://doi.org/10.1007/ s00146-017-0736-1.

Chin W.W. (2010). How to write up and report PLS analyses. In V.E. Vinzi, W.W. Chin, J. Henseler and H. Wang (eds.), Handbook of Partial Least Squares. London: Springer.

. (1998). The partial least squares approach to structural equation modeling. Modern Methods for Business Research, 295(2): 295-336.

Chin, W.W. and Newsted, P.R. (1999). Structural equation modeling analysis with small samples using partial least squares. In R.H. Hoyle (ed.), Statistical Strategies for Small Sample Research. Thousand Oaks, CA: Sage Publications, 307-341.

Cohen, J. (1988). Statistical Power Analysis for the Behavioural Sciences. 2nd Ed. Hillsdale, Ml: N.J. Lawrence Earlbaum Associates Inc.

Davcik, N.S. (2014). The use and misuse of structural equation modelling in management research: A review and critique. Journal of Advances in Management Research, 11(1): 47-81. https://doi.org/10.1108/JAMR-07-2013 $-0043$. 
Emmanouilidis, C. and Komonen, K. (2013). Physical asset management practices in industry: Comparisons between Greece and other EU countries. In IFIP International Conference on Advances in Production Management Systems. Berlin, Heidelberg: Springer, 509-516. Available at: https://link .springer.com/chapter/10.1007/978-3-642-41263-9_63.

Estache, A. and De Rus, G. (2000). Privatization and Regulation of Transport Infrastructure: Guidelines for Policymakers and Regulators. Washington, DC: World Bank Publications.

Field, A. (2016). An Adventure in Statistics: The Reality Enigma. Thousand Oaks, CA: Sage Publications.

Fornell, C. and Larcker, D.F. (1981). Evaluating structural equation models with unobservable variables and measurement error. Journal of Marketing Research, 18(1): 39-50. https://doi.org/10.1177/002224378101800104.

Gaetani, E., Aniello, L., Baldoni, R., Lombardi, F., Margheri, A. and Sassone, V. (2017). Blockchain-based database to ensure data integrity in cloud computing environments. Available at: http://eprints.soton.ac.uk/id/eprint/41 1996.

Gambo, N., Said, I. and Inuwa, I.I. (2017). Client financial support for mitigating cost factors affecting the performance of small-scale contractors in Nigeria. ATBU Journal of Environmental Technology, 10(1): 119-138.

Gambo, N., Said, I. and Ismail, R. (2016a). Comparing the levels of performance of small-scale local government contractors in Northern Nigeria with international practice. Engineering Construction and Architectural Management, 23(5): 588-609. https://doi.org/10.1 108/ECAM-12-2014-0155.

(2016b). Influences of cost factors affecting the technical performance of local government projects in Nigeria: A partial least square-structural equation modelling (PLS-SEM) approach. Journal of Construction in Developing Countries, 21(1): 85-111. http://dx.doi.org/ 10.21315/jcdc2016.21.1.5.

Giudici, P. (2003). Applied Data Mining Statistical Method for Business and Industry. London: Wiley.

Gunarathna, P. and Hassan, R. (2016). Sustainability assessment tool for road transport asset management practice. Road and Transport Research, 25(4): $15-26$.

Guthrie, G. (2010). Basic Research Methods: An Entry to Social Science Research. New Delhi: SAGE Publications India.

Hair, J.F., Ringle, C.M. and Sarstedt, M. (2011). PLS-SEM: Indeed, a silver bullet. Journal of Marketing Theory and Practice, 19(2): 139-151. https://doi.org/10.2753/ MTP1069-6679190202.

Hair, J.F., Sarstedt, M., Hopkins, L.G. and Kuppelwieser, V.G. (2014). Partial least squares structural equation modelling (PLS-SEM) An emerging tool in business research. European Business Review, 26(2): 106-121. https://doi.org/10.1108/ EBR-10-2013-0128.

Hazen, B.T., Boone, C.A., Ezell, J.D. and Jones-Farmer, L.A. (2014). Data quality for data science, predictive analytics and big data in supply chain management: An introduction to the problem and suggestions for research and applications. International Journal of Production Economics, 154: 72-80. https://doi.org/10.1016/j.ijpe.2014.04.018. 
Hazen, B.T., Overstreet, R.E. and Boone, C.A. (2015). Suggested reporting guidelines for structural equation modelling in supply chain management research. The International Journal of Logistics Management, 26(3): 627-641. https://doi .org/10.1108/IJLM-08-2014-0133.

Ho, R. (2006). Handbook of Univariate and Multivariate Data Analysis and Interpretation with SPSS. Boca Raton, FL: Chapman and Hall/CRC.

Hu, L. and Bentler, P.M. (1999). Cutoff criteria for fit indexes in covariance structure analysis: Conventional criteria versus new alternatives. Structural Equation Modelling: A Multidisciplinary Journal, 6(1): 1-55. https://doi.org/ 10.1080/10705519909540118.

Hulland, J. (1999). Use of partial least squares (PLS) in strategic management research: A review of four recent studies. Strategic Management Journal, 20(2): 195-204. https://doi.org/10.1002/(SICI) 1097-0266(199902)20:2<195::AID -SMJ13>3.0.CO;2-7.

Jazdi, N. (2014). Cyber-physical systems in the context of Industry 4.0. In 2014 IEEE International Conference on Automation, Quality and Testing, Robotics. Cluj-Napoca, Romania: IEEE. https://doi.org/10.1 109/AQTR.2014.6857843.

Jraiw, K. (2003). Urban road transport in Asia's developing countries: Safety and efficiency strategy. Transportation Research Record, 1846(1): 19-25. https://doi.org/10.3141/1846-04.

Kalitanyi, V. and Goldman, G.A. (2020). Human capital management in the fourth industrial revolution. In S.O. Atiku (ed.), Human Capital Formation for the Fourth Industrial Revolution. Hershey, PA: IGI Global, 100-126. https://doi .org/10.4018/978-1-5225-9810-7.ch005.

Kock, N. (2016). Advantages of nonlinear over segmentation analyses in path models. International Journal of e-Collaboration, 12(4): 1-6. https://doi.org/ 10.4018/IJeC.2016100101.

(2012). Warp PLS 3.0 User Manual. Laredo, TX: Script Warp Systems. Available at: http://cits.tamiu.edu/WarpPLS/UserManual_v_5_0.pdf.

Krejcie, R.V. and Morgan, D.W. (1970). Determining sample size for research activities. Educational and Psychological Measurement, 30(3): 607-610. https://doi.org/10.1177/001316447003000308.

Labor, C. (1990). Industrial revolution. Available at: https://www.westada.org/ cms/lib8/ID01904074/Centricity/Domain/2066/child\%20labor\%20slide.pdf.

Li, G., Hou, Y. and Wu, A. (2017). Fourth industrial revolution: Technological drivers, impacts and coping methods. Chinese Geographical Science, 27(4): 626637.

Liao, Y., Loures, E. R., Deschamps, F., Brezinski, G. and Venâncio, A. (2018). The impact of the fourth industrial revolution: A cross-country/region comparison. Production, 28: e20180061. http://dx.doi.org/10.1590/0103-6513 .20180061 .

Lim, T., Porras-Alvarado, J.D. and Zhang, Z. (2019). Pricing of highway infrastructure for transportation asset management. Built Environment Project and Asset Management, 9(1), 64-79. https://doi.org/10.1 108/BEPAM-05-2018-0083.

MacCallum, R.C, Browne, M.W and Sugawara, H.M. (1996). Power analysis and determination of sample size for covariance structure modelling. Psychological Methods, 1(2): 130-149. 
Manesh, M.F., Pellegrini, M.M., Marzi, G. and Dabic, M. (2020). Knowledge management in the fourth industrial revolution: Mapping the literature and scoping future avenues. IEEE Transactions on Engineering Management. https://doi.org/10.1109/TEM.2019.2963489.

Marcelino, P., Antunes, M.L. and Fortunato, E. (2019). Current international practices on pavement condition assessment. In M. Crispino (ed.), Pavement and Asset Management. Leiden: CRC Press/Balkema, 359-364.

Martin, T., Davey, S. and Clarke, M. (2019). Data standard for road management and investment in Australia and New Zealand (No. AP-R597-19). Available at: http://worldcat.org/isbn/9781925854008.

Mazzi, A. (2020). Environmental sustainability to support competitiveness: From theory to practice. In C. Silvestri, M. Piccarozzi and B. Aquilani (eds.), Customer Satisfaction and Sustainability Initiatives in the Fourth Industrial Revolution. Hershey, PA: IGI Global, 99-124. https://doi.org/10.4018/978-1 -7998-1419-1.ch006.

McNabb, D.E. (2010). Research Methods for Political Science: Qualitative and Quantitative Methods. New York: ME Sharpe.

Meyer, M.D., Amekudzi, A. and O'Har, J.P. (2010). Transportation asset management systems and climate change: Adaptive systems management approach. Transportation Research Record, 2160(1): 12-20. https://doi.org/ $10.3141 / 2160-02$.

Momotova, O.N., Zhdanova, O.V., Maksimov, V.Y., Labovskaya, Y.V. and Shevchenko, E.A. (2020). Features and problems of innovative development of the Russian economy under the conditions of the "fourth industrial revolution". In E. Popkova (ed.), Growth Poles of the Global Economy: Emergence, Changes and Future Perspectives. Cham, Switzerland: Springer, 347-355. https://doi.org/10.1007/978-3-030-15160-7_36.

Morrar, R., Arman, H. and Mousa, S. (2017). The fourth industrial revolution (Industry 4.0): A social innovation perspective. Technology Innovation Management Review, 7(11): 12-20.

Nangoy, R., Mursitama, T., Setiadi, N. and Pradipto, Y. (2020). Creating sustainable performance in the fourth industrial revolution era: The effect of employee's work well-being on job performance. Management Science Letters, 10(5): 1037-1042. https://doi.org/10.5267/j.msl.2019.11.006.

Naudé, W. (2017). Entrepreneurship, education and the fourth industrial revolution in Africa. Available at: https://papers.ssrn.com/sol3/papers.cfm?abstract_ id $=2998964$.

NBD (Nigerian Business Directory) (2019). List of companies in Nigeria with contact details, Addresses. Available at: https://www.google.com/ search? $q=$ Nigerian+Business + directory+2019\&oq=Nigerian+Business +directory+2019\&aqs=chrome..69i57j33i10i160.26070j0j7\&sourceid =chrome\&ie=UTF-8.

NBS (Nigeria Bureau of Statistics) (2018). Road transport accident data in the Federal Republic of Nigeria. Available at: http://www.nigerianstat.gov.ng/ pdfuploads/Road_Transport_Data_-_Q2_2018.pdf.

Ng, H.S. (2020). Opportunities, challenges and solutions for Industry 4.0. In A.Ö. Tunç and P. Aslan (eds.), Business Management and Communication Perspectives in Industry 4.0. Hershey, PA: IGI Global, 32-51. https://doi.org/ 10.4018/978-1-5225-9416-1.ch003. 
Oppenheim, A.N. (2000). Questionnaire Design, Interviewing and Attitude Measurement. London/New York: Continuum.

Pallant, J. (2011). SPSS Survival Manual 4th edition: A Step by Step Guide to Data Analysis Using SPSS Version 18. Maidenhead, Berkshire: Open University Press.

Park, H. (2016). Are we ready for the fourth industrial revolution? Yearbook of Medical Informatics, 25(1): 1-3. https://doi.org/10.15265/IY-2016-052.

Peters, M.A. (2017). Technological unemployment: Educating for the fourth industrial revolution. Journal of Self-Governance and Management Economics, 5(1): 25-33. https://doi.org/10.1080/00131857.2016.1177412.

Petrillo, A., Felice, F.D., Cioffi, R. and Zomparelli, F. (2018). Fourth industrial revolution: Current practices, challenges and opportunities. In A. Petrillo (ed.), Digital Transformation in Smart Manufacturing. London: IntechOpen Limited, 1-20.

Piryonesi, S.M. and El-Diraby, T.E. (2020). Data analytics in asset management: Cost-effective prediction of the pavement condition index. Journal of Infrastructure Systems, 26(1), 04019036. https://doi.org/10.1061/(ASCE)IS.1943 $-555 X .0000512$.

Piyatrapoomi, N., Kumar, A. and Setunge, S. (2004). Framework for investment decision-making under risk and uncertainty for infrastructure asset management. Research in Transportation Economics, 8: 199-214. https://doi.org/10.1016/S0739-8859(04)08010-2.

Schraven, D., Hartmann, A. and Dewulf, G. (2011). Effectiveness of infrastructure asset management: challenges for public agencies. Built Environment Project and Asset Management, 1 (1): 61-74. https://doi.org/10.1 108/2044124 1111143786.

Schreiber, J.B., Nora, A., Stage, F.K., Barlow, E.A. and King, J. (2006). Reporting structural equation modelling and confirmatory factor analysis results: A review. The Journal of Educational Research, 99(6): 323-338. https://doi .org/10.3200/JOER.99.6.323-338.

Sekaran, U. and Bougie, R. (2011). Research Methods for Business: A Skill Building Approach. New Jersey: John Wiley and Sons Ltd.

Simmons, G., Palmer, M. and Truong, Y. (2013). Inscribing value on business model innovations: Insights from industrial projects commercializing disruptive digital innovations. Industrial Marketing Management, 42(5): 744-754. https://doi.org/10.1016/j.indmarman.2013.05.010.

Stăncioiu, A. (2017). The fourth industrial revolution "Industry 4.0". Facilitate şi Durabilitate, 1:74-78. Available at: http://www.utgjiu.ro/rev_mec/mecanica/ pdf/2017-01/11_Alin\%20ST\%C4\%82NCIOIU\%20-\%20THE\%2OFOURTH\%20 INDUSTRIAL\%20REVOLUTION\%20\%E2\%80\%9EINDUSTRY\%204.0\%E2\%80\%9D.pdf

Sumner, M. and Slattery, D. (2010). The impact of leadership effectiveness and team processes on team performance in construction. International Journal of Construction Education and Research, 6(3): 179-201. https://doi.org/10 $.1080 / 15578771.2010 .507720$

Sutherland, E. (2020). The fourth industrial revolution: The case of South Africa. Politikon, 47(2): 233-252. https://doi.org/10.1080/02589346.2019.1696003.

Switzer, A. and McNeil, S. (2004). Developing a road map for transportation asset management research. Public Works Management and Policy, 8(3), 162-175. https://doi.org/10.1177/1087724X03259475. 
Syam, N. and Sharma, A. (2018). Waiting for a sales renaissance in the fourth industrial revolution: Machine learning and artificial intelligence in sales research and practice. Industrial Marketing Management, 69: 135-146. https://doi.org/10.1016/j.indmarman.2017.12.019.

Xiong, B., Skitmore, M. and Xia, B. (2015). A critical review of structural equation modelling applications in construction research. Automation in Construction, 49: 59-70. https://doi.org/10.1016/j.autcon.2014.09.006.

XU, M., David, J.M. and Kim, S.H. (2018). The fourth industrial revolution: Opportunities and challenges. International Journal of Financial Research, 9(2): 90-95. https://doi.org/10.5430/ijfr.v9n2p90. 